\title{
THE NATURALIST ON HORSEBACK
}

E. OTTO HOHN, Department of Physiology, University of Alberta, Edmonto

If you are both an enthusiastic wildlife observer and a horseman you will sooner or later want to enjoy both activities simultaneously - can it be done? The short and practical answer is - not very well - but that is putting it in a nutshell. There are a number of considerations and qualifications.

If you are prepared to look at birds and the larger mammals with the naked eye, you can do that almost as well from the saddle as on foot. But the use of binoculars is tricky, because no horse, in my admittedly limited experience, ever stands still for as long as you may wish it to. You can stop it from moving on, easily enough, but you can't reduce it to total immobility; and this, an absolute requisite for a satisfactory look with binoculars, imposes a fundamental limit on the combination of riding with bird or mammal watching in the ordinary sense. However, riding and spotting without binoculars can be satisfactory to the extent that in a familiar bit of country you can identify most birds and large mammals by their naked-eye appearance. Some of your bird identifications, based on glimpses and hearing songs or calls, may however be probabilities based on knowing what to expect in each habitat, rather than certainties.
As an adjunct to naked-eye $b$ watching, riding has evident adv tages over walking. You can let horse do the rough and tiring worl mud and rough vegetation as wel up hill and down dale, and if it is $u$ to water, in marshes as well. In 19? spent some months about a la marsh in the pampas of Argent The local horses, bred on the ma would wade without hesitation in lagoons, which had amazingly $f$ bottoms, to any depth short of which would have forced them swim. Here birding on horseback preferable to the alternatives wading or the labor of pushing a $k$ through the dense stands of rushes. To see grebes, cormor and limpkins, and to peer into $t$ nests or those of everglade kites $f$ the saddle was a rare experienc was not convinced that birds wo allow me to approach them close horseback than on foot. This seem to contradict the late 19th early 20th century British natur Abel Chapman's successful use stalking horse in the Coto Donar southern Spain, for goose shootir the turn of the century. But I bel he walked behind a horse and dic ride it, and it is quite conceivable some birds are so used to gra horses that they will accept a ch

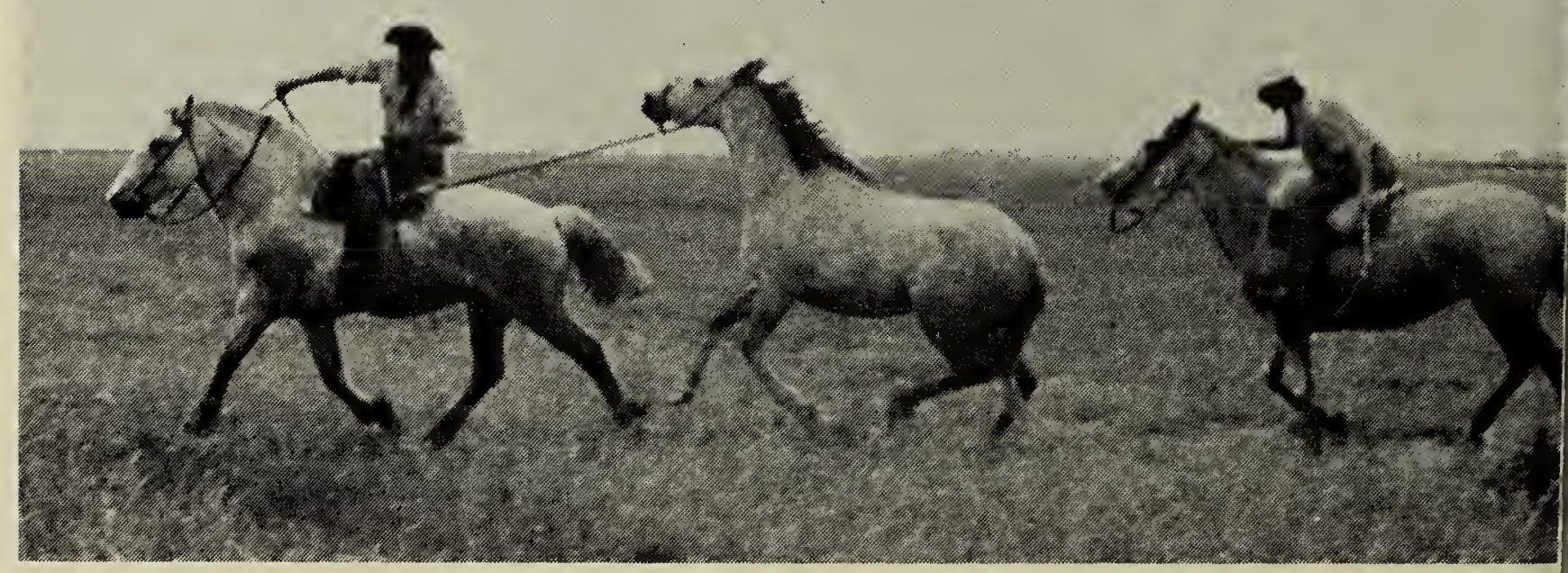

Breaking horses

E. Otto 


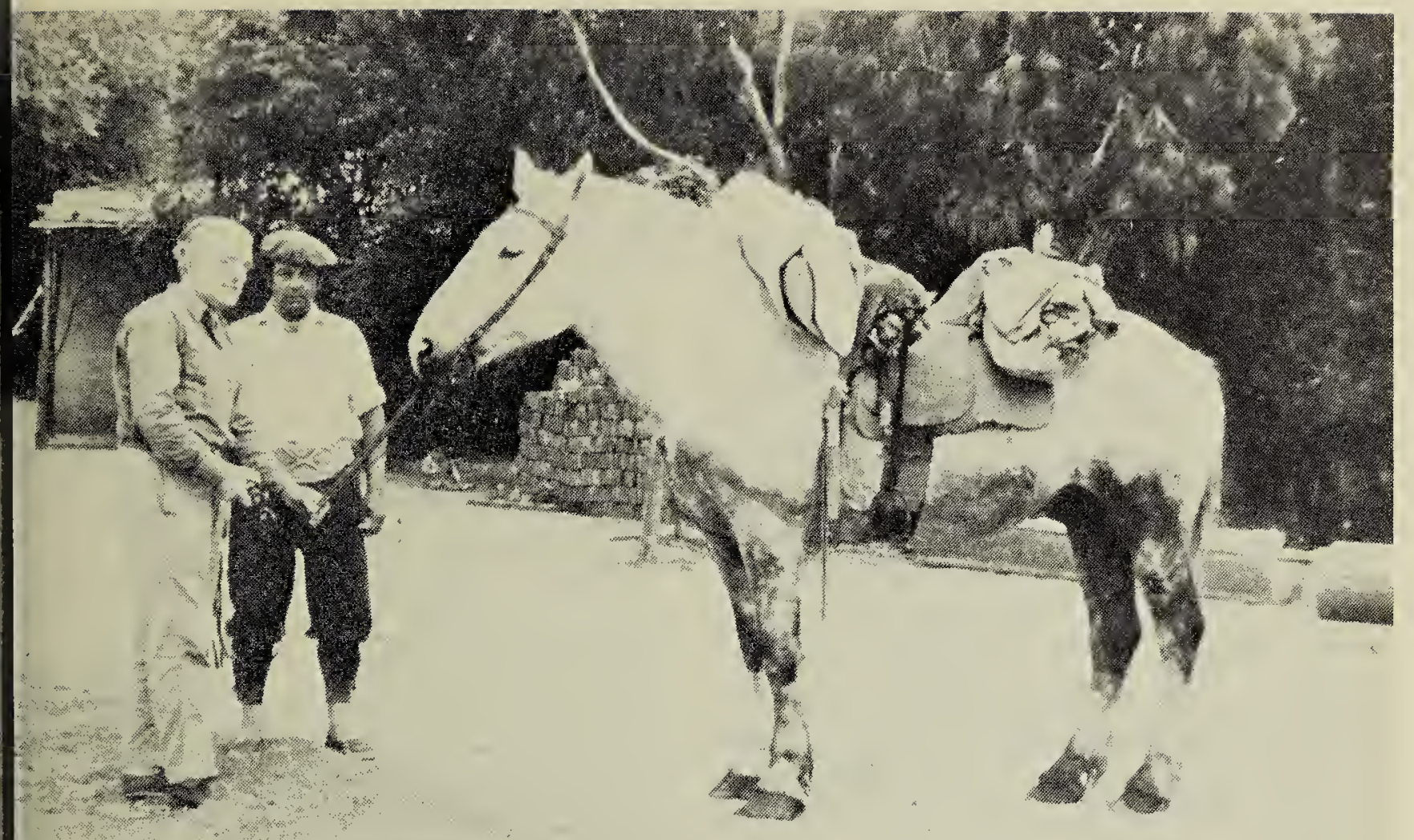

ed-up for an overnight collecting trip

E. Otto Hohn

oach by these before flushing they will by a man mounted or t.

llecting is perhaps nowadays not of bird watching for many; but as ysiologist needing samples of enine glands of certain birds, I have occasion to do it using horses. I t know whether cavalry armed carbines always dismounted to t, but I've always been warned to shoot from horseback but to instead of a few yards away from horse. One of the horses at my osal in Argentina was excellent his sort of work - I was collecting ted snipe. I would ride him over looded pastures until we flushed of the birds, dismount and walk - a snipe where l'd marked its ent after its usually short flight. ers were generally close by. The e set to grazing as soon as 1 ped the reins and he stayed re he was until I was ready to e on. Not so with a mare I was loaned for work in this marsh slowly took off for home after I ounted and was busy. Fortunateintervening fence stopped her really getting away on me.
Though I shot dismounted, the horse was a great asset in this collecting for it saved me a lot of walking over grassland under a few inches of water to get to the general area where the snipe were, and within that area to get from one group of birds to another.

So much for naked-eye bird watching and collecting with the help of a horse.

It is when one tries to use binoculars in the saddle that problems really arise. I imagine most people will feel like myself - that when a bird is sighted there is generally not enough time to extricate the binoculars from their case and that they should therefore be carried at the ready. If you do this on horseback you will find that the neck straps are of such a length that the binoculars hang too low and are cruelly bumped about by the saddle bow during a trot or canter. You have to shorten the straps so that you can only just swing the binoculars clear of your chin when you bring them up to your eyes. Even then you will want to steady them when the horse is in any 
of its faster gaits by clamping them under one arm, holding them in one hand or pushing them down the front of a tightly-buttoned jacket or windbreaker.

With these precautions the binoculars will stay pretty close to where you want them whatever (short of jumping, which I've not tried with binoculars) you make the horse do. The great flaw, however, as I've already remarked, is that no horse with which I have had experience can be relied upon to stand absolutely still for more than a very few seconds so that satisfactory views through binoculars, though possible, are rare. Of course, you can get such a view by dismounting, but one is always reluctant to do this from sheer laziness and because a strange horse cannot always be relied upon to stay in place when the bridle is allowed to hang, as western-trained horses are supposed to; nor will it necessarily follow readi- ly wherever you may try to lead it order to get a good view of your bi

Most of these difficulties minimal with a horse with which 0 has become familiar and perhaps, I've not yet experienced this, th could be nearly abolished by train it very carefully and patiently.

A last point: if like myself you apt to let your thoughts wan whenever your body is temporaril some steady state, don't ever let y mind become completely absork in your inner world when you are the saddle. Any horse with some sp is liable to make a surprise move time. For example, one of my Arg tine mounts, after carrying me cal through paths that ran among serr masses of five-foot high thistles, wl we were happily cantering ove rough pasture suddenly shied a single clump of thistles out in open.

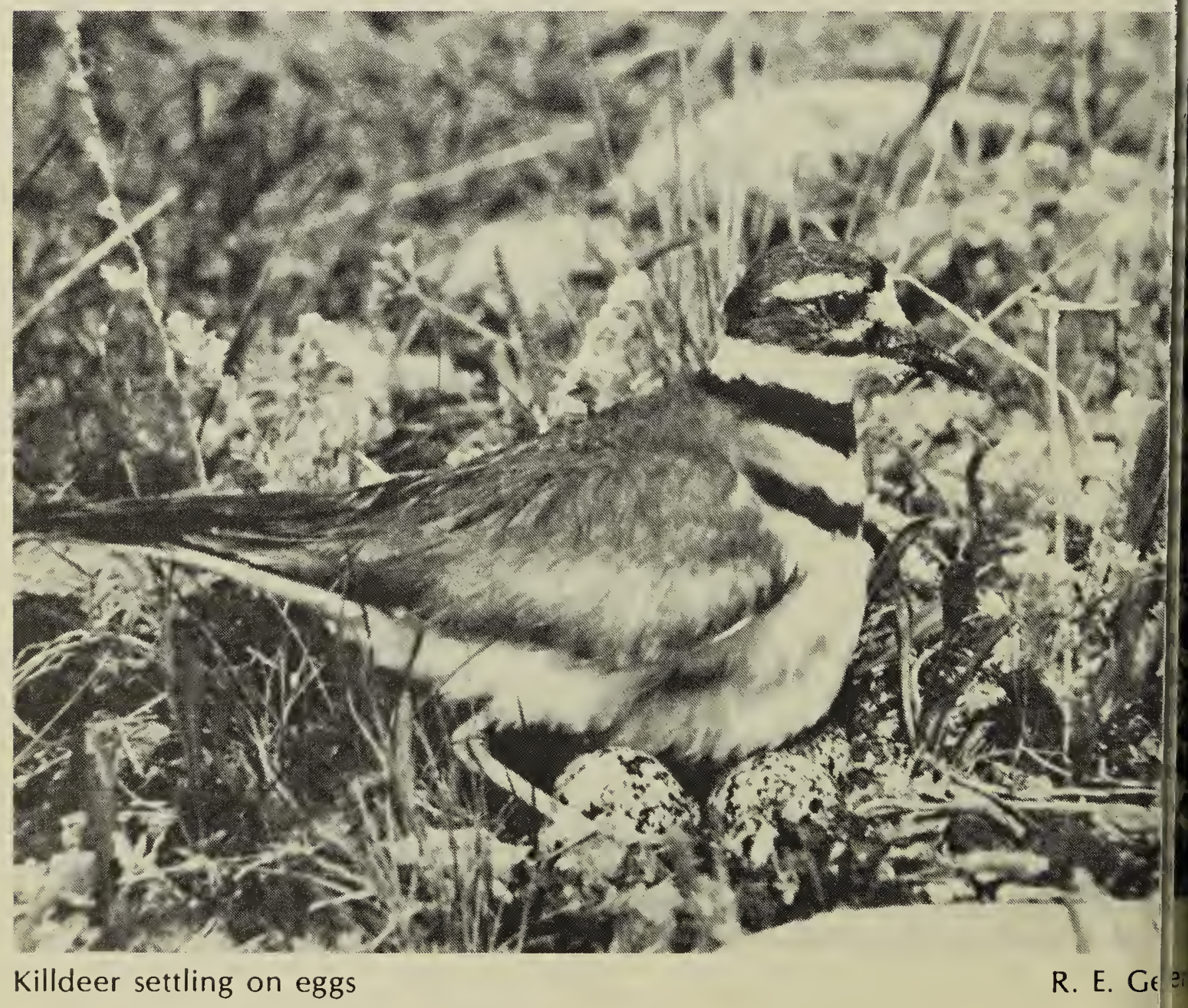

